\title{
Phenolic Composition and Antioxidant Activities of Different Solvent Extracts from Pine Needles in Pinus Species
}

\author{
Yoon-Han Kang ${ }^{1 \dagger}$ and Luke R. Howard ${ }^{2}$ \\ ${ }^{1}$ Department of Food Science, Gangneung-Wonju National University, Gangwon 210-702, Korea \\ ${ }^{2}$ Department of Food Science, University of Arkansas, Fayetteville, AR 72704, USA
}

\begin{abstract}
The purpose of this study was to investigate the phenolic acid, proanthocyanidin (PAs), and flavonol glycoside contents, as well as the antioxidant activities of pine needle extracts from six species of young pine trees. The extracts were prepared from Section Pinus (Diploxylon): $P$. densiflora, $P$. sylvestris, $P$. pinaster and $P$. pinea, and Section Strobus (Haploxylon): $P$. koraiensis and $P$. strobus. Phenolics were extracted from pine needles with $80 \%$ acetone to obtain the soluble free fraction, and insoluble residues were digested with $4 \mathrm{M} \mathrm{NaOH}$ to obtain bound ethyl acetate and bound water fractions. Phenolics were analyzed by HPLC, and the hydrophilic antioxidant activity was measured using oxygen radical absorbance capacity (ORAC). Total phenolic and flavonoid contents of the soluble free fraction were higher than those of the bound ethyl acetate and bound water fractions. The main phenolics were monomers and polymers of PAs in the soluble free fraction, and phenolic acids and flavonol glycosides in bound ethyl acetate fraction. Flavonol glycosides found in different species of pine needles were qualitatively similar within fractions, but composition varied among Pinus sections. High levels of kaempferol arabinoside and an unknown compound were present in all Strobus species. The soluble free fraction had the highest antioxidant activity, followed by bound ethyl acetate and bound water fractions.
\end{abstract}

Key words: pine needles, solvent extract, flavonol glycosides, proanthocyanidins, antioxidant activity

\section{INTRODUCTION}

Two main classifications of Genus Pinus were evaluated in this research: Section Pinus (Diploxylon) and Section Strobus (Haploxylon). The former species are $P$. densiflora, $P$. sylvestris, $P$. pinaster and $P$. pinea, and the latter species are $P$. koraiensis and $P$. strobus. This classification into the two Sections is based on leaf, cone and seed characteristics (1).

Previous reports have shown that Genus Pinus contains bioactive substances including antioxidant phenolics from extracts of pine needles $(2,3)$ and pine bark $(4,5)$. However, most of the previous reports only analysed the soluble phenolics extracted using water, acetone or methanol. The main phenolic compounds previously identified included phenolic acids (6), proanthocyanidins (PAs) (7), and flavonol glycosides $(8,9)$.

Phenol-rich plant extracts may play an important role in health promotion through numerous mechanisms, including antioxidant activity, as reported for flavanols from grape seed extracts (10) and ginkgo flavonoids (11). Kaempferol from Ginkgo biloba extract inhibited pancreatic cancer cell growth and induced cell apoptosis in vitro in a concentration dependent manner, and may have clinical applications as adjuvant therapy in the treatment of pancreatic cancer (11). Little information exists, however, regarding the characterization and content of cell wall bound phenolics from waste pine needle residue (12). Several recent studies have reported on the biological significance and activity of phenolic acids (13), flavonoids (14) and proanthocyanidins (15-17) in a variety of plants.

A previous study was conducted to determine the flavonol and tannin contents and antioxidant activity of hot water and $70 \%$ acetone extracts from pine needle (18). Rats fed a high fat diet plus pine needle extract supplement for 4 weeks demonstrated reduced weight gain and reduced serum and liver lipids (19). According to the determination of total phenolics, including both soluble free and bound forms from $80 \%$ acetone in common fruits, cranberry, had the highest soluble free phenolic content, followed by apple, red grape, strawberry, lemon, peach, orange, banana, pear, and pineapple. Pineapple had the highest bound phenolic content (20). These results suggest that in some plants, the phenolics may be highly bound to the cell wall and the concentration of phenolics may be underestimated if the bound fraction is not measured. It is well established that plant extracts

${ }^{\dagger}$ Corresponding author. E-mail: yhkang@gwnu.ac.kr

Phone: +82-33-640-2966, Fax: +82-33-640-2966 
containing high levels of phenolics exhibit strong free radical scavenging capacity, and the two variables are highly correlated $(21,22)$.

In the present study, we investigated the contents of PAs in soluble free (Soluble-F) fraction, and phenolic acids and flavonols in bound ethyl acetate (Bound-E) fraction. Additionally, ORAC in all fractions from six pine species was determined.

\section{MATERIALS AND METHODS}

\section{Materials}

Pine needle trees were purchased from Forest Farm (Williams, OR, USA), and included four species of Pinus ( $P$. densiflora, $P$. sylvestris, $P$. pinaster, $P$. pinea) and two species of Strobus ( $P$. koraiensis and P. strobus). The growth periods of all six species were 2,4 , $2,2,3$, and 3 years, respectively, and the plant heights were $47,70,142,60,78$, and $52 \mathrm{~cm}$, respectively. The lengths of pine needles evaluated were $6.5,5.5,12,2.5$, 10 , and $8 \mathrm{~cm}$, respectively. The pine needles were dried in a forced air oven at $55^{\circ} \mathrm{C}$ until constant weight was obtained, ground to pass through a $1 \mathrm{~mm}$ screen, and stored at $4^{\circ} \mathrm{C}$.

\section{Preparation of pine needle extracts}

Pine needles extracts and fractions were prepared by the method of Sun et al. (20). A flow chart of the extraction process used to isolate soluble free (Soluble-F), bound ethyl acetate (Bound-E) and bound water (Bound-W) fractions from various pine needles is shown in Fig. 1. For the preparation of Soluble-F, $1 \mathrm{~g}$ of dried pine needles was extracted with $150 \mathrm{~mL}$ of chilled $80 \%$ acetone by blending with a Euro Turrax T18 Tissuemizer (Tekmar-Dohrmann Corp, Mason, OH, USA) 3 times for 5 min each time. Homogenates were filtered through filter paper (Whatman No. 1), and the filtrates were evaporated to dryness using a SpeedVac ${ }^{\circledR}$ concentrator (ThermoSavant, Holbrook, NY, USA) and reconstituted in $50 \mathrm{~mL}$ of distilled water. For preparation of Bound-E fraction, the residues from Soluble $\mathrm{F}$ were collected and hydrolyzed with $20 \mathrm{~mL}$ of $4 \mathrm{M} \mathrm{NaOH}$ at room temperature for $24 \mathrm{hr}$. After hydrolysis, the solutions were centrifuged for $5 \mathrm{~min}$ at $5000 \mathrm{rpm}$. The supernatant was neutralized with concentrated hydrochloric acid and extracted three times with ethyl acetate. Ethyl acetate extracts were evaporated to dryness using a SpeedVac ${ }^{\circledR}$ concentrator and resuspended in $10 \mathrm{~mL}$ of distilled water. For preparation of Bound-W, the remaining water soluble portion was evaporated to dryness using the SpeedVac $^{\circledR}$, and then reconstituted in $10 \mathrm{~mL}$ of water. All fractions were stored at $-70^{\circ} \mathrm{C}$ prior to total phenolic,

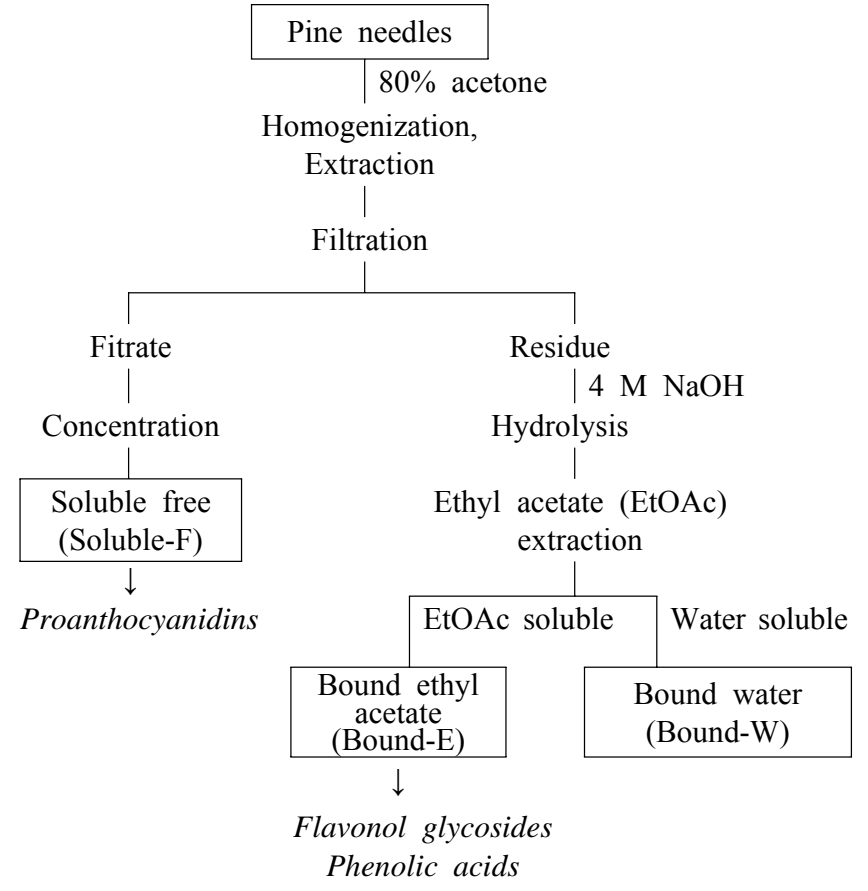

Fig. 1. Flow chart of extraction process and phenolic analysis for soluble free, bound ethyl acetate and bound water fractions from various pine needles.

total flavonoid, proanthocyanidins (PAs) and antioxidant capacity analyses. One extraction was prepared from each species of pine needle, and each analysis was performed in triplicate.

\section{Detemination of total phenolics and flavonoids}

Total phenolics in the fractions were determined with Folin-Ciocalteu reagent according to the method of Slinkard and Singleton (23) with gallic acid as a standard. Results are expressed as $\mathrm{mg} / \mathrm{g}$ dry weight. Total flavonoids in the fractions were analyzed by the method of Eum et al. (24). Naringin was used as standard with results expressed as $\mathrm{mg} / \mathrm{g}$ dry weight.

\section{HPLC analysis of flavonol glycosides and proantho- cyanidins}

HPLC analysis of flavonol glycosides: Bound-E fraction was passed through $0.45 \mu \mathrm{m}$ filters (Whatman, Clifton, NJ, USA) prior to HPLC analysis. Samples (50 $\mu \mathrm{L})$ were analysed using a Waters HPLC system (Waters Corp, Milford, MA, USA) (Table 1) (25). Separation was performed on a $250 \times 4.6 \mathrm{~mm}$ Aqua $\mathrm{C}_{18}$ (Phenomenex, Torrance, Calif, USA) column using a binary gradient of A, 2\% acetic acid and B, $0.5 \%$ acetic acid in water : acetonitrile $(1: 1 \mathrm{v} / \mathrm{v})$ at a flow rate of 1.0 $\mathrm{mL} / \mathrm{min}$. The linear gradient was: $90 \% \mathrm{~A}$ to $45 \% \mathrm{~A}$ from $0 \sim 50 \mathrm{~min} ; 45 \%$ A to $0 \%$ A from $50 \sim 60 \mathrm{~min}$; $0 \%$ A to $90 \%$ A from $60 \sim 65$ min. Peaks were monitored at wavelengths of $320 \mathrm{~nm}$ (phenolic acids) and 
Table 1. Peak assignments, retention times (RT) and mass spectral data of p-coumaric acid hexoside and flavonols detected in various pine needles

\begin{tabular}{|c|c|c|c|c|}
\hline \multirow{2}{*}{ Peak } & \multirow{2}{*}{ HPLC RT (min) } & \multirow{2}{*}{ Identification } & \multicolumn{2}{|c|}{$(\mathrm{m} / \mathrm{z})$ values } \\
\hline & & & $\mathrm{M}^{-}$ & Fragments \\
\hline 1 & 27.8 & Protocatechuic acid hexoside & 315 & 153 \\
\hline 2 & 30.9 & $p$-Coumaric acid hexoside & 325 & 163 \\
\hline 3 & 32.5 & Unknown & & \\
\hline 4 & 34.3 & Unknown & & \\
\hline 5 & 37.2 & Quercetin galactoside & 463 & 301 \\
\hline 6 & 38.0 & Quercetin glucoside & 463 & 301 \\
\hline 7 & 41.0 & Kaempferol galactoside & 447 & 284 \\
\hline 8 & 42.2 & Quercetin pentoside & 433 & 301 \\
\hline 9 & 42.8 & Kaempferol glucoside & 447 & 284 \\
\hline 10 & 43.8 & Isorhamnetin glucoside & 477 & 314 \\
\hline 11 & 47.7 & Kaempferol arabinoside & 417 & 284 \\
\hline 12 & 49.5 & Unknown & 461 & 298 \\
\hline 13 & 51.3 & Unknown & 461 & 298 \\
\hline
\end{tabular}

$360 \mathrm{~nm}$ (flavonols) using a Waters model 996 photodiode array detector. Phenolic acids and flavonol glycosides were expressed as $\mu \mathrm{g} p$-coumaric acid and $\mu \mathrm{g}$ quercetin-3- $\beta$-glucoside equivalents per $\mathrm{g}$ dry weight, respectively, using external calibration curves of authentic standards.

HPLC analysis of proanthocyanidins: Soluble-F fraction $(7 \mathrm{~mL})$ was loaded onto a Sepdadex LH-20 column $(6 \times 1.5 \mathrm{~cm})$, previously equilibrated in $30 \%(\mathrm{v} / \mathrm{v})$ aqueous methanol (26). The column was washed with $40 \mathrm{~mL}$ of $30 \%$ methanol to remove contaminants, and proanthocyanidins were then eluted from the column with $70 \mathrm{~mL}$ of $70 \%$ acetone. The resulting extract was evaporated to dryness using a SpeedVac concentrator and reconstituted with $2 \mathrm{~mL}$ of solvent (acetone: water: acetic acid, 70:29.5:0.5). Samples were passed through 0.45 $\mu \mathrm{m}$ filters (Waters), and then $5 \mu \mathrm{L}$ were analyzed using a Waters HPLC system (Milford, MA, USA). Separation was performed on a $250 \times 4.6 \mathrm{~mm}$ Luna silica column (Phenomenex, Torrance, CA, USA) using a binary gradient consisting of $\mathrm{A}$, dichloromethane:methanol : water : acetic acid $(82: 14: 2: 2 \mathrm{v} / \mathrm{v} / \mathrm{v} / \mathrm{v})$, and $\mathrm{B}$, methanol : water : acetic acid $(96: 2: 2 \mathrm{v} / \mathrm{v} / \mathrm{v})$ at a flow rate of $0.8 \mathrm{~mL} / \mathrm{min}$. The linear gradient was: $100 \%$ A to $88.3 \%$ A from 0 $20 \mathrm{~min} ; 88.3 \%$ A to $74.4 \%$ A from $20 \sim 50 \mathrm{~min} ; 74.4 \%$ A to $12.3 \%$ A from $50 \sim 55 \mathrm{~min} ; 12.3 \% \mathrm{~A}$ to $12.3 \%$ A from $55 \sim 65 \mathrm{~min}$; and $12.3 \% \mathrm{~A}$ to $100 \% \mathrm{~A}$ from $65 \sim 70 \mathrm{~min}$. The peaks were monitored by fluorescence detection with excitation at $276 \mathrm{~nm}$ and emission at 316 $\mathrm{nm}$ using a Waters model 474 fluorescence detector. Proanthocyanidin monomers and polymers were quantified as monomer equivalents using standards previously isolated from cocoa that were provided by Mars Inc. (Hackettstown, NJ, USA). Results were expressed as mg per $g$ dry weight.

\section{HPLC/MS analysis of flavonols}

An analytical Hewlet Packard 1100 series HPLC (Palo Alto, CA, USA) equipped with an autosampler, binary HPLC pump and UV/VIS detector was used for HPLC/MS analysis. Flavonols were separated using the HPLC conditions described above with detection at 360 $\mathrm{nm}$. The HPLC was interfaced to a Bruker (Billerica, MA, USA) model Esquire-LC/MS ion trap mass spectrometer, equipped with Bruker software, which controlled the instrument and collected the signal at 360 $\mathrm{nm}$. Conditions for mass spectral analysis in the negative ion electrospray mode included a capillary voltage of $4000 \mathrm{~V}$, a nebulising pressure of $30.0 \mathrm{psi}$, a drying gas flow of $9.0 \mathrm{~mL} / \mathrm{min}$ and a temperature of $300^{\circ} \mathrm{C}$. Data were collected using the full scan mode over a mass range of $\mathrm{m} / \mathrm{z} 500 \sim 1000$ at $1.0 \mathrm{sec}$ per cycle. Peak assignments based upon characteristic ions are shown in Table 1. For compounds in which chemical standards were commercially available, retention times were also used to confirm their identity.

\section{Detemination of antioxidant activity}

The oxygen radical absorbance capacity (ORAC) of each fraction of pine needle extracts was measured using the method of Prior et al. (27) modified for use with a FLUOstar Optima microplate reader (BMG Labtechnologies, Durham, NC, USA). Soluble-F, Bound-E, and Bound-W pine needle extracts were diluted 50,000, 5,000, 5,000-fold, respectively, with $75 \mathrm{mM}$ phosphate buffer ( $\mathrm{pH}$ 7.0) prior to ORAC analysis. The assay was carried out at $37^{\circ} \mathrm{C}$ in clear 48 -well Falcon plates (VWR, St. Louis, MO). A standard curve was obtained by plotting four concentrations of Trolox against the net area under the curve (AUC) of each standard. Final ORAC values were calculated using the regression equation between Trolox concentration and AUC and are expressed 


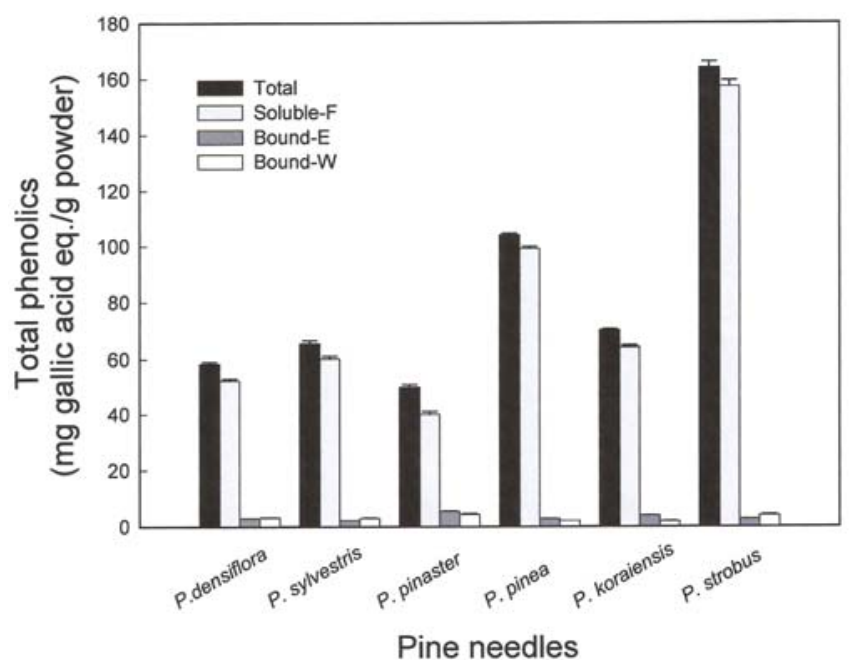

Fig. 2. Total phenolics in soluble free, bound ethyl acetate, and bound water fractions from various pine needles. Values are mean $\pm \mathrm{SD}$ of triplicate measurements.

as $\mu \mathrm{M}$ of Trolox equivalents per gram dry weight.

\section{Statistical analysis}

The experimental data were analyzed with JMP software (Version 8, SAS Institute, NC, USA). Results are expressed as mean values \pm standard deviation.

\section{RESULTS AND DISCUSSION}

\section{Total polyphenol and flavonoids}

The total phenolic contents of the three fractions, including their sum, from the six pine needle species are shown in Fig. 2. Among all pine needles analyzed, $P$. strobus had the highest Soluble-F phenolic content $(157.1 \pm 2.0 \mathrm{mg} / \mathrm{g})$, followed by $P$. pinea $(99.1 \pm 0.7$ $\mathrm{mg} / \mathrm{g})$, P. koraiensis $(64.3 \pm 0.4 \mathrm{mg} / \mathrm{g})$, P. sylvestris $(60.1 \pm 1.0 \mathrm{mg} / \mathrm{g})$, P. densiflora $(52.2 \pm 0.7 \mathrm{mg} / \mathrm{g})$, and P. pinaster $(40.0 \pm 1.0 \mathrm{mg} / \mathrm{g})$. $P$. pinaster had the highest Bound-E phenolic content $(5.4 \pm 0.1 \mathrm{mg} / \mathrm{g})$, followed by P. koraiensis $(3.9 \pm 0.1 \mathrm{mg} / \mathrm{g})$, P. densiflora $(2.9 \pm 0.1$ $\mathrm{mg} / \mathrm{g}), P$. pinea $(2.8 \pm 0.1 \mathrm{mg} / \mathrm{g}), P$. strobus $(2.7 \pm 0$ $\mathrm{mg} / \mathrm{g})$, and $P$. sylvestris $(2.3 \pm 0 \mathrm{mg} / \mathrm{g})$. $P$. pinaster had the highest Bound-W phenolic content $(4.4 \pm 0.3 \mathrm{mg} / \mathrm{g})$, followed by, $P$. strobus $(4.0 \pm 0.2 \mathrm{mg} / \mathrm{g}), P$. densiflora $(3.2 \pm 0.1 \mathrm{mg} / \mathrm{g}), P$. syvestris $(3.0 \pm 0.1 \mathrm{mg} / \mathrm{g}), P$. pinea $(2.1 \pm 0 \mathrm{mg} / \mathrm{g})$, and $P$. koraiensis $(1.8 \pm 0.1 \mathrm{mg} / \mathrm{g})$. The phenolic content of the Soluble-F fraction was higher than that of Bound-E and Bound-W fractions. P. strobus had the highest total phenolic (Soluble-F + Bound-E + Bound-W) content $(163.8 \pm 2.1 \mathrm{mg} / \mathrm{g})$, followed by $P$. pinea $(103.9 \pm 0.4 \mathrm{mg} / \mathrm{g}), P$. koraiensis $(70.0 \pm 0.4 \mathrm{mg} / \mathrm{g})$, P. sylvestris $(65.3 \pm 1.1 \mathrm{mg} / \mathrm{g})$, P. densiflora $(58.3 \pm 0.7$ $\mathrm{mg} / \mathrm{g}$ ), and $P$. pinaster $(49.8 \pm 1.0 \mathrm{mg} / \mathrm{g})$.

The flavonoid contents of the three fractions from the

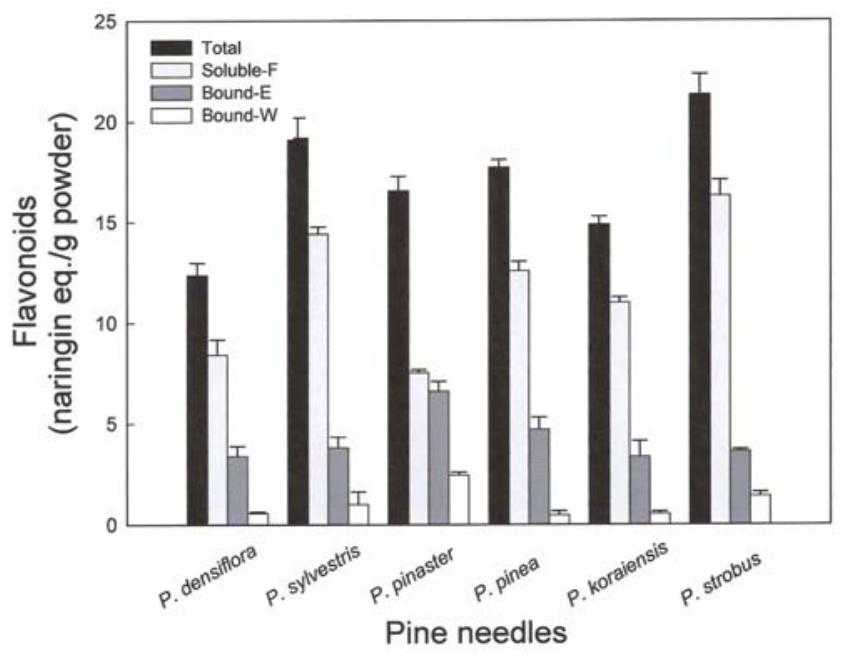

Fig. 3. Total flavonoids in soluble free, bound ethyl acetate, and bound water fractions from various pine needles. Values are mean $\pm \mathrm{SD}$ of triplicate measurements.

six pine needle species are shown in Fig. 3. Among all the pine needles analyzed, $P$. strobus had the highest Soluble-F flavonoid content $(16.3 \pm 0.8 \mathrm{mg} / \mathrm{g})$, followed by $P$. sylvestris $(14.4 \pm 0.4 \mathrm{mg} / \mathrm{g}), P$. pinea $(12.6 \pm 0.5$ $\mathrm{mg} / \mathrm{g}), P$. koraiensis $(11.0 \pm 0.3 \mathrm{mg} / \mathrm{g}), P$. densiflora $(8.4 \pm 0.8 \mathrm{mg} / \mathrm{g})$, and $P$. pinaster $(7.5 \pm 0.2 \mathrm{mg} / \mathrm{g}) . P$. pinaster had the highest Bound-E flavonoid content $(6.6 \pm 0.5 \mathrm{mg} / \mathrm{g})$, followed by $P$. pinea $(4.7 \pm 0.6 \mathrm{mg} / \mathrm{g})$, P. sylvestris $(3.8 \pm 0.5 \mathrm{mg} / \mathrm{g}), P$. strobus $(3.6 \pm 0.1 \mathrm{~m} / \mathrm{g})$, $P$. densiflora $(3.4 \pm 0.5 \mathrm{mg} / \mathrm{g})$, and $P$. koraiensis $(3.3 \pm 0.8 \mathrm{mg} / \mathrm{g})$. Among all the species, the pine needles of $P$. pinaster had the highest ratio of total flavonoids to total phenolics. P. pinaster had the highest Bound-W flavonoid content $(2.4 \pm 0.2 \mathrm{mg} / \mathrm{g})$, followed by $P$. strobus $(1.4 \pm 0.2 \mathrm{mg} / \mathrm{g}), P$. sylvestris $(1.0 \pm 0.6 \mathrm{mg} / \mathrm{g}), P$. densiflora $(0.6 \pm 0.1 \mathrm{mg} / \mathrm{g}), \quad P$. koraiensis $(0.5 \pm 0.1$ $\mathrm{mg} / \mathrm{g})$, and $P$. pinea $(0.5 \pm 0.2 \mathrm{mg} / \mathrm{g})$.

The flavonoid contents of the Soluble-F fractions were higher than those of Bound-E and Bound- $\mathrm{W}$ fractions. $P$. strobus had the highest total flavonoid (Soluble-F + Bound-E + Bound-W) content $(21.3 \pm 1.0 \mathrm{mg} / \mathrm{g})$, followed by $P$. sylvestris $(19.2 \pm 1.0 \mathrm{mg} / \mathrm{g}), \quad P$. pinea $(17.7 \pm 0.4 \mathrm{mg} / \mathrm{g})$, . pinaster $(16.6 \pm 0.70 \mathrm{mg} / \mathrm{g}), P$. koraiensis $(14.9 \pm 0.4 \mathrm{mg} / \mathrm{g})$, and $P$. densiflora $(12.4 \pm 0.6$ $\mathrm{mg} / \mathrm{g})$.

\section{Flavonol glycosides}

The HPLC profiles of phenolic acids and flavonol glycosides detected at $320 \mathrm{~nm}$ and $360 \mathrm{~nm}$, respectively, in the bound ethyl acetate fraction of pine needles are shown in Fig. 4. Peak 1 was tentatively identified as protocatechuic acid hexoside, and peak 2 was tentatively identified as $p$-coumaric acid hexoside, while peaks 3 and 4 represent unknown phenolic acids. The flavonol 

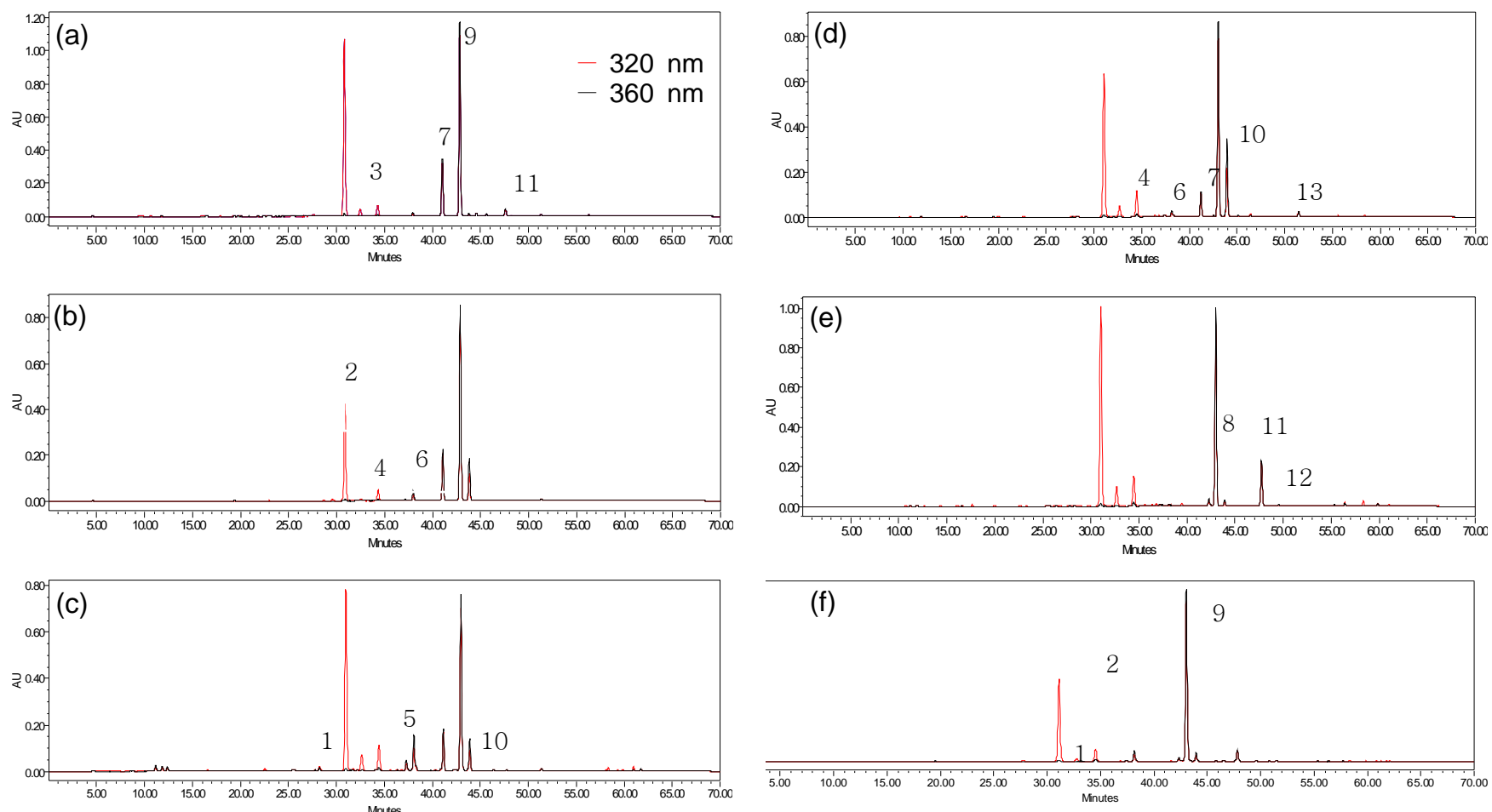

Fig. 4. Detection of flavonol glycosides $(360 \mathrm{~nm})$ and phenolic acids $(320 \mathrm{~nm})$ in bound ethyl acetate fraction of various pine needles. (a) P. densiflora, (b) P. sylvestris, (c) P. pinaster, (d) P. pinea, (e) P. koraiensis, and (f) P. strobus. See Table 1 for peak identification.

glycosides detected at $360 \mathrm{~nm}$ in pine needles were identified as quercetin galactoside (peak 5), quercetin glucoside (peak 6), kaempferol galactoside (peak 7), quercetin pentoside (peak 8), kaempferol glucoside (peak 9), isorhamnetin glucoside (peak 10), and kaempferol arabinoside (peak 11), while peaks 12 and 13 represent unknown flavonols. Flavonol glycosides found in different species of pine needles were qualitatively similar within fractions, but composition varied among Pinus sections. Previous reports mainly focused on soluble fractions, but in our study various kaempferol glycosides were identified that have not been identified previously. The total phenolic acid contents of bound ethyl acetate fractions in the six pine needles ranged from $2483.6 \mu \mathrm{g} / \mathrm{g}$ in $P$. sylvestris to $6631.2 \mu \mathrm{g} / \mathrm{g}$ in $P$. koraiensis (Table 2). The total flavonol glycoside content of the six pine needles ranged from $1924.2 \mu \mathrm{g} / \mathrm{g}$ in $P$. sylvestris to $2983.1 \mu \mathrm{g} / \mathrm{g}$ in P. strobus.

In terms of composition, $p$-coumaric acid hexoside was the predominant phenolic acid, and kaempferol glu-

Table 2. Flavonol glycoside and p-coumaric acid contents of bound ethyl acetate fraction in various pine needles

\begin{tabular}{|c|c|c|c|c|c|c|c|}
\hline \multirow{2}{*}{\multicolumn{2}{|c|}{ Compound }} & \multicolumn{6}{|c|}{ Pine needles } \\
\hline & & P. densiflora & P. sylvestris & P. pinaster & P. pinea & P. koraiensis & P. strobus \\
\hline $1^{1)}$ & Protocatechuic acid hexoside & $63.2 \pm 0.4$ & 0 & $97.7 \pm 5.1$ & $10.2 \pm 2.0$ & $24.2 \pm 1.0$ & $36.6 \pm 0.5$ \\
\hline $2^{1)}$ & $p$-Coumaric acid hexoside & $5644.5 \pm 32.9^{3)}$ & $2209.0 \pm 15.5$ & $4118.4 \pm 25.7$ & $3311.0 \pm 28.6$ & $5267.0 \pm 38.5$ & $4115.0 \pm 17.4$ \\
\hline $3^{1)}$ & & $215.2 \pm 1.2$ & $44.6 \pm 0.3$ & $391.5 \pm 6.1$ & $258.7 \pm 3.8$ & $543.0 \pm 2.9$ & $130.4 \pm 0.7$ \\
\hline $4^{1)}$ & & $340.1 \pm 2.6$ & $230.0 \pm 0.9$ & $578.3 \pm 2.8$ & $602.9 \pm 6.6$ & $797.0 \pm 3.1$ & $571.0 \pm 3.1$ \\
\hline $5^{2)}$ & Quercetin galactoside & $8.6 \pm 0.2$ & $6.2 \pm 0.9$ & $76.4 \pm 2.9$ & $18.2 \pm 1.3$ & $19.9 \pm 5.2$ & $4.0 \pm 0.8$ \\
\hline $6^{2)}$ & Quercetin glucoside & $\begin{array}{r}0.0 \pm 0.2 \\
25.0 \pm 5.9\end{array}$ & $48.2 \pm 12.1$ & $261.5 \pm 14.3$ & $41.4 \pm 14.6$ & $13.2 \pm 0.4$ & $153.4 \pm 8.8$ \\
\hline $7^{2)}$ & Kaempferol galactoside & $512.7 \pm 38.2$ & $331.4 \pm 13.9$ & $281.0 \pm 13.0$ & $151.7 \pm 20.7$ & 0 & 0 \\
\hline $8^{2)}$ & Quercetin pentoside & $7.0 \pm 3.2$ & 0 & $5.7 \pm 0.3$ & $5.4 \pm 0.4$ & $61.1 \pm 0.5$ & $52.8 \pm 1.8$ \\
\hline $9^{2)}$ & Kaempferol glucoside & $1752.8 \pm 110.2$ & $1278.0 \pm 73.6$ & $1185.6 \pm 33.0$ & $1305.1 \pm 71.0$ & $1546.7 \pm 21.5$ & $2481.6 \pm 66.9$ \\
\hline $10^{2)}$ & Isorhamnetin glucoside & $18.3 \pm 1.5$ & $246.7 \pm 60.0$ & $221.7 \pm 6.9$ & $467.7 \pm 106.2$ & $48.4 \pm 0.2$ & $117.3 \pm 3.3$ \\
\hline $11^{2)}$ & Kaempferol arabinoside & $63.2 \pm 3.7$ & $3.9 \pm 0.4$ & $4.7 \pm 0.1$ & $2.1 \pm 0.5$ & $362.4 \pm 7.2$ & $165.2 \pm 6.2$ \\
\hline $12^{2)}$ & & $4.7 \pm 1.0$ & $0.6 \pm 0.4$ & $1.4 \pm 0.3$ & 0 & $8.0 \pm 0.6$ & $5.6 \pm 0.7$ \\
\hline $13^{2)}$ & & $15.1 \pm 0.4$ & $9.2 \pm 0.1$ & $13.5 \pm 1.0$ & $33.8 \pm 3.1$ & $2.4 \pm 0.1$ & $3.2 \pm 0.6$ \\
\hline
\end{tabular}

${ }^{1)}$ Data expressed as $p$-coumaric acid. ${ }^{2)}$ Quercetin glucoside equivalents. ${ }^{3)} \mu \mathrm{g} / \mathrm{g}$ dry weight pine needle. 
coside was the predominant flavonol glycoside in the six types of pine needles. Typically, the flavonols that were present in large amounts in all pine needles were in glycoside forms: however, the levels of flavonol glycosides in the four Pinus (Section) species (P. densiflora, $P$. sylvestris, $P$. pinaster, $P$. pinea) were different from the two Strobus species (P. koraiensis, $P$. strobus). Kaempferol galactoside was present only in Pinus species, whereas quercetin pentoside was present only in Strobus species. High levels of kaempferol arabinoside and unknown compound 12 were present in all the Strobus species.

$P$. koraiensis and $P$. strobus also contained low levels of unknown compound 13 compared to the four Pinus species. The only flavonols that were previously identified in Pinus were the 3-O-glucosides of kaempferol and isorhamnetin, taxifolin 7-glucoside, and mono- and di-coumaroyl-glucosides of kaempferol (28). We did not detect taxifolin 7-glucoside or the mono- and di-coumaroyl-glucosides of kaempferol in our samples. The content of $p$-coumaric acid hexoside ranged from 2209 $\mu \mathrm{g} / \mathrm{g}$ in $P$. sylvestris to $5644.5 \mu \mathrm{g} / \mathrm{g}$ in $P$. densiflora. The content of kaempferol glucoside ranged from 1185.6 $\mu \mathrm{g} / \mathrm{g}$ in $P$. pinaster to $2481.6 \mu \mathrm{g} / \mathrm{g}$ in $P$. strobus. The content of isorhamnetin glucoside ranged from $18.3 \mu \mathrm{g} / \mathrm{g}$ in $P$. densiflora to $467.7 \mu \mathrm{g} / \mathrm{g}$ in $P$. pinea. In a recent study, kaempferol was reported to be an effective in- hibitor of human cytochrome P450 enzymes, an important step in cancer chemoprevention (29). Due to an abundance of kaempferol glycosides, pine needle extracts appear to be an excellent candidate for further study involving chemopreventive properties.

\section{Proanthocyanidins}

Fig. 5 shows chromatograms representing proanthocyanidins in the soluble-F fraction following a Sephadex LH-20 column clean-up step. A peak with retention time of $13.5 \mathrm{~min}$ was consistent with the retention time of a proanthocyanidin monomer standard, while the peak with a retention time of $57 \mathrm{~min}$ represented proanthocyanidin polymers with degree of polymerization greater than 10 .

$(+)$ Catechin and proanthocyanidins in common foods are well known for health beneficial effects $(30,31)$. Proanthcyanidins, also known as condensed tannins, are oligomeric and polymeric flavan-3-ols. The compounds that consist exclusively of (epi)catechin are called procyanidins (PCs).

The content of $(+)$ catechin ranged from $0.97 \mathrm{mg} / \mathrm{g}$ in $P$. pinaster to $2.84 \mathrm{mg} / \mathrm{g}$ in $P$. densiflora, while the content of polymers ranged from $0.74 \mathrm{mg} / \mathrm{g}$ in $P$. koraiensis to $13.5 \mathrm{mg} / \mathrm{g}$ in $P$. pinea (Table 3 ). We suspect that the actual concentration of polymers in the extracts may actually be much higher because an authentic standard of polymers was unavailable, and the peaks were
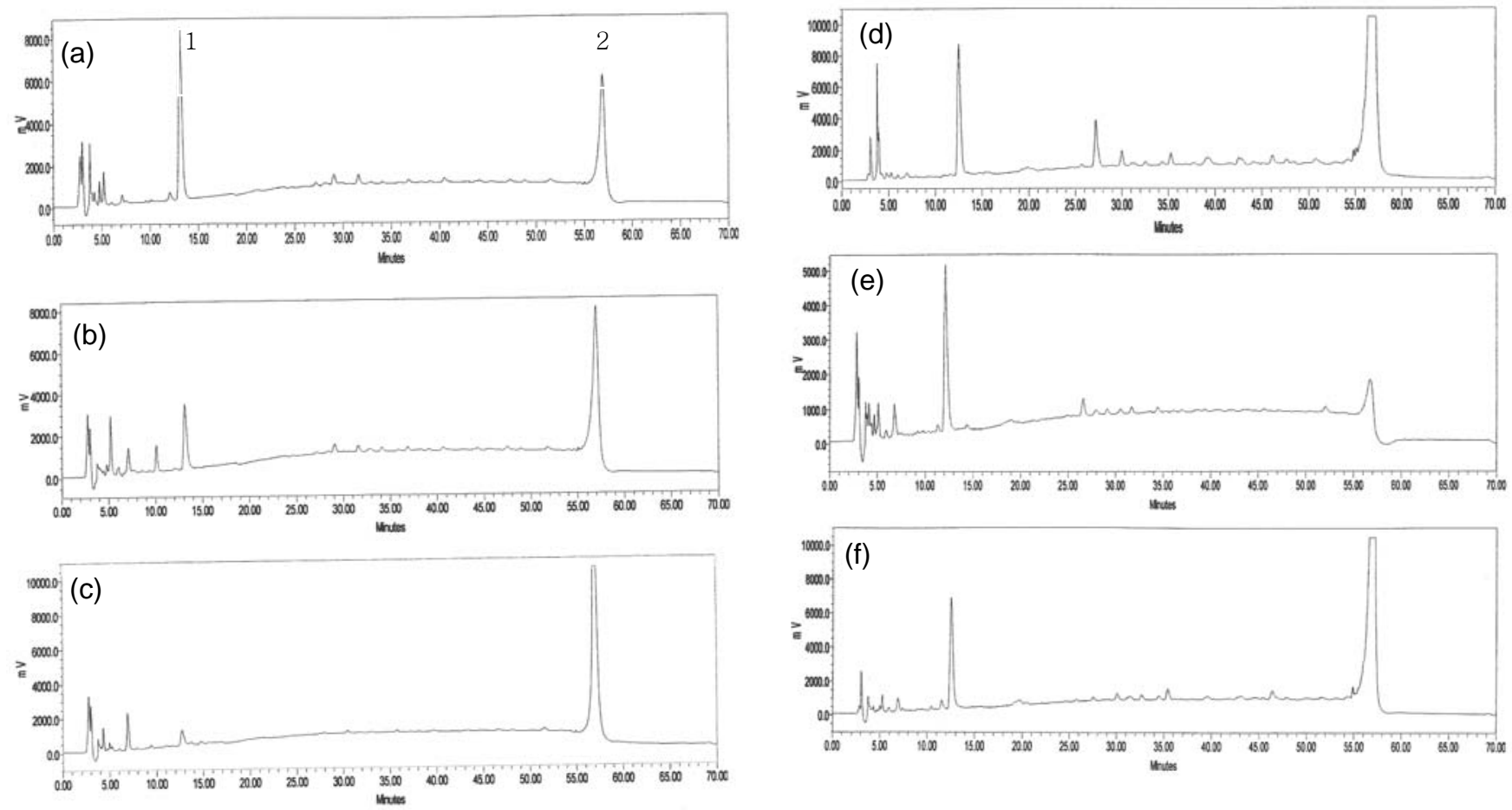

Fig. 5. Detection of proanthocyanidins in soluble free fraction of various pine needles. (a) P. densiflora, (b) P. sylvestris, (c) P. pinaster, (d) P. pinea, (e) P. koraiensis, and (f) P. strobus. Peak 1, monomer; catechin, 2; polymer. 
Table 3. Proanthocyanidins content of soluble free fraction in various pine needles

\begin{tabular}{lrrrc}
\hline & Monomer & Polymer & Total & $\begin{array}{c}\text { Percent of total } \\
\text { phenolic } \\
\text { content }\end{array}$ \\
\hline P. densiflora & $2.84 \pm 0.33^{2)}$ & $3.81 \pm 0.09$ & 6.65 & 12.7 \\
P. sylvestris & $1.30 \pm 0.58$ & $5.65 \pm 0.63$ & 6.96 & 11.6 \\
P. pinaster & $0.97 \pm 1.61$ & $5.93 \pm 1.61$ & 6.90 & 17.3 \\
P. pinea & $2.59 \pm 0.17$ & $13.49 \pm 0.44$ & 16.09 & 16.2 \\
P. koraiensis & $1.23 \pm 0.09$ & $0.74 \pm 0.23$ & 1.96 & 3.0 \\
P. strobus & $2.05 \pm 0.08$ & $10.52 \pm 0.30$ & 12.57 & 8.0
\end{tabular}

${ }^{1)}$ Data expressed as cocoa proanthocyanidin equivalents.

${ }^{2)} \mathrm{mg} / \mathrm{g}$ dry weight pine needle.

quantified as monomer equivalents. Consistent with our findings, a hot water extract from Pinus radiate bark contained ample quantities of polymeric proanthocyanidins (DP $>13$ ), comprising 94\% of total procyanidins (5). However, the total proanthocyanidin content $(4.5 \mathrm{mg} / \mathrm{g}$ extract) determined by the HCl-butanol method of a hot water extract obtained from Pinus densiflora (7) was much lower than the values obtained in this study.

\section{Antioxidant activity}

Antioxidant capacities of the six pine needle species are shown in Fig. 6. P. strobus had the highest Soluble-F antioxidant activity $(1223.3 \pm 12.6 \mu$ mole Trolox $/ \mathrm{g})$, followed by $P$. pinea $(901.5 \pm 35.2 \mu$ mole Trolox $/ \mathrm{g})$, P. sylvestris $(560.0 \pm 36.3 \mu$ mole Trolox $/ \mathrm{g})$, P. pinaster $(478.8$ $\pm 32.8 \mu$ mole Trolox $/ \mathrm{g})$, P. densiflora $(466.1 \pm 27.3$ $\mu$ mole Trolox $/ \mathrm{g})$, and P. koraiensis $(402.0 \pm 7.5 \mu$ mole Trolox/g).

$P$. pinaster had the highest Bound-E antioxidant activity $(128.0 \pm 9.6 \mu$ mole Trolox/g), followed by $P$. koraiensis $(111.6 \pm 6.2 \mu$ mole Trolox $/ \mathrm{g}), \quad P$. sylvestris

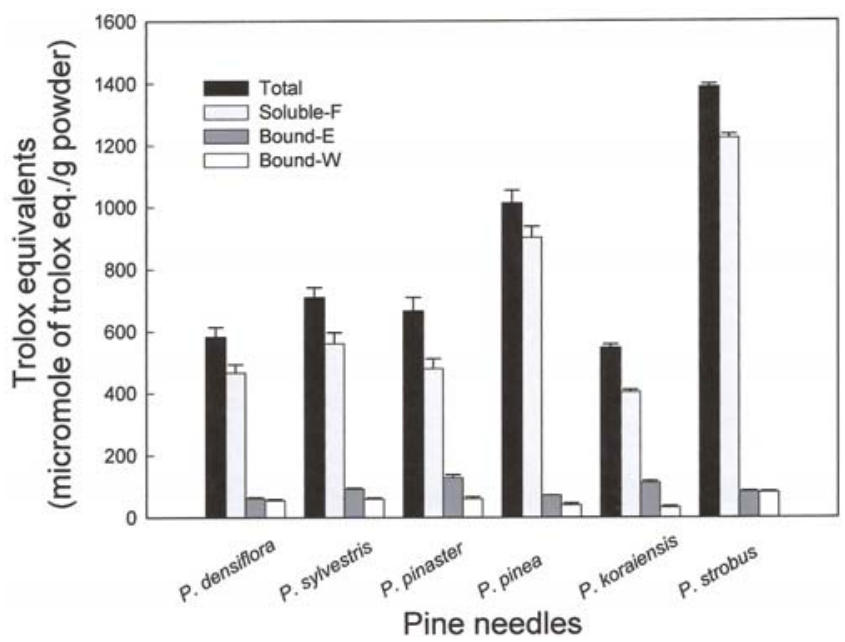

Fig. 6. Oxygen radical absorbing capacity (ORAC) in the soluble free, bound ethyl acetate, and bound water fraction of various pine needles. Values are mean $\pm \mathrm{SD}$ of triplicate measurements.
$(91.7 \pm 3.2 \mu$ mole Trolox $/ \mathrm{g}), \quad$ P. strobus $(82.3 \pm 3.1$ umole Trolox $/ \mathrm{g}), P$. pinea $(70.9 \pm 0.9 \mu$ mole Trolox $/ \mathrm{g})$, and $P$. densiflora $(61.4 \pm 3.7 \mu$ mole Trolox $/ \mathrm{g})$.

$P$. strobus had the highest Bound-W antioxidant activity $(81.3 \pm 2.4 \mu$ mole Trolox $/ g)$, followed by $P$. pinaster $(60.2 \pm 7.1 \mu$ mole Trolox $/ \mathrm{g}), P$. sylvestris $(59.3 \pm 4.0$ umole Trolox/g), P. densiflora $(55.3 \pm 2.8 \quad \mu$ mole Trolox $/ \mathrm{g}), P$. pinea $(39.7 \pm 5.5 \mu$ mole Trolox $/ \mathrm{g})$, and $P$. koraiensis $(32.0 \pm 4.5 \mu$ mole Trolox/g).

The antioxidant capacities of the Soluble-F fractions of the six pine needles were higher than those of Bound-E and Bound-W fractions. P. strobus had the highest total antioxidant (Soluble-F + Bound-E + Bound-W) capacity $(1386.8 \pm 10.5 \mu$ mole Trolox $/ g)$, followed by $P$. pinea $(1012.1 \pm 40.3 \mu$ mole Trolox $/ \mathrm{g}), P$. sylvestris $(710.7 \pm 31.7 \mu$ mole Trolox $/ \mathrm{g}), P$. pinaster $(667.0 \pm 43.4 \mu \mathrm{mole}$ Trolox $/ \mathrm{g}), \quad P$. densiflora (582.7 $\pm 31.1 \mu$ mole Trolox $/ \mathrm{g}$ ), and P. koraiensis (545.6 \pm 11.4 $\mu$ mole Trolox/g). This work confirms that free and cell wall bound phenolics in pine needle extracts exhibit total antioxidant activity.

\section{ACKNOWLEDGEMENTS}

Kang Yoon-han wishes to express gratitude to Cindi R. Brownmiller for her help in instrumental analysis, and to Dr. Mi Jin Cho for her advice on the data processing. This study was supported by Gangneung-Wonju National University Research Fund in 2008.

\section{REFERENCES}

1. Kong WS. 2006. Biogeography of native Korean Pinaceae. J Korean Geogra Soc 41: 73-93.

2. Turunen M, Heller W, Stich S, Sandermann H, Sutinen ML, Norokorpi Y. 1999. The effect of UV exclusion on the soluble phenolics of young Scots pine seedling in the subarctic. Environ Pollut 106: 219-228.

3. Martz F, Sutinen ML, Derome K, Wingsle G, JulkunenTiitto R, Turunen M. 2007. Effects of ultraviolet (UV) exclusion on the seasonal concentration of photosynthetic and UV-screening pigments in Scots pine needles. Global Change Biol 13: 252-265.

4. Packer L, Rimbach G, Virgili F. 1999. Antioxidant activity and biologic properties of a procyanidin-rich extract from pine (Pinus maritima) bark, pycnogenol. Free Radic Biol Med 27: 704-724.

5. $\mathrm{Ku} \mathrm{CS}$, Mun SP. 2008. Antioxidant properties of monomeric, oligomeric, and polymeric fraction in hot water extract from Pinus radiata bark. Wood Sci Technol 42: 47-60.

6. Pasqualini V, Robles C, Garzino S, Greff S, BousquetMelou A, Bonin G. 2003. Phenolic compounds content in Pinus halepensis Mill. needles: a bioindicator of air polution. Chemosphere 52: 239-248.

7. Lee $\mathrm{OH}$, Kim KY, Jang MK, Yu KH, Kim SG, Kim MH, 
Lee SH. 2008. Evaluation of proanthocyanidin contents in total polyphenolic compounds of pine (Pinus densiflora) needle extracts and their antioxidative activities. $J$ Life Sci 18: 213-219.

8. Lavola A, Aphalo PJ, Lahti M, Julkunen-Tiitto R. 2003. Nutrient availability and the effect of increasing UV-B radiation on secondary plant compounds in Scots pine. Environ Exp Bot 49: 49-60.

9. Roitto M, Rautio P, Julkunen-Tiitto R, Kukkola E, Huttunen S. 2005. Changes in the concentrations of phenolics and photosynthates in Scots pine (Pinus sylvestris L.) seedlings exposed to nickel and copper. Environ Pollut 137: 603-609.

10. Bozan B, Tosun G, Özcan D. 2008. Study of polyphenol content in the seeds of red grape (Vitis vinifera L.) varieties cultivated in Turkey and their antiradical activity. Food Chem 109: 426-430.

11. Zhang Y, Chen AY, Li M, Chen C, Yao Q. 2008. Ginkgo biloba extract kaempferol inhibits cell proliferation and induces apoptosis in pancreatic cancer cells. J Surg Res 148: 17-23.

12. Strack D, Heilemann J, Momken M, Wray V. 1998. Cell wall-conjugated phenolics from coniferae leaves. Phytochemistry 27: 3517-3521.

13. Boudet AM. 2007. Evolution and current status of research in phenolic compounds. Phytochemistry 68: 2722-2735.

14. Williams RJ, Spencer JPE, Rice-Evan C. 2004. Flavonoids: antioxidants or signaling molecules? Free Radic Biol Med 36: 838-849.

15. Marles MAS, Ray H, Gruber MY. 2003. New perspectives on proanthocyaninidin biochemistry and molecular regulation. Phytochemistry 64: 367-383.

16. Xie DY, Dixon RA. 2005. Anthocyanidin biosynthesis still more questions than answers? Phytochemistry 66: 2127-2144.

17. Prior RL, Gu L. 2005. Occurrence and biological significance of proanthocyanidins in the American diet. Phytochemistry 66: 2264-2280.

18. Kang YH, Park YK, Oh SR, Moon KD. 1995. Studies on the physiological functionality of pine needle and mugwort extracts. Korean J Food Sci Technol 27: 978-984.

19. Kang YH, Park YK, Ha TY, Moon KD. 1996. Effect of pine needle extracts on serum and liver lipid contents in rats fed high fat diet. J Korean Soc Food Nutr 25: 367373.

20. Sun J, Chu YF, Wu X, Liu RH. 2002. Antioxidant and antiproliferative activities of common fruits. J Agric Food Chem 50: 7449-7454.

21. Kang YH, Park YK, Lee GD. 1996. The nitrite scavenging and electron donating ability of phenolic compounds. Korean J Food Sci Technol 28: 232-239.

22. Howard LR, Clark JR, Brownmiller C. 2003. Antioxidant capacity and phenolic content in blueberries as affected by genotype and growing season. J Sci Food Agric 83: 1238-1247.

23. Slinkard K, Singleton VL. 1997. Total phenol analysis: automation and comparison with manual methods. Am J Enol Vitic 28: 49-55.

24. Eum MA, Kang YH, Kwon DJ, Jo KS. 1999. The nitrite scavenging and electron donating ability of potato extracts. Korean J Food Nutr 12: 478-483.

25. Schieber A, Keller P, Carle R. 2001. Determination of phenolic acids and flavonoids of apple and pear by high-performance liquid chromatography. J Chromatogr 910: 265-373.

26. Gu L, Kelm MA, Hammerstone J, Beecher G, Holden J, Haytowitz D, Prior RL. 2003. Screening of foods containing proanthocyanidins and their structural characterization using LC-MS/MS and thiolytic degradation. J Agric Food Chem 51: 7513-7521.

27. Prior RL, Hoang H, Gu L, Wu X, Bacchiocca M, Howard L, Hampsch-Woodill M, Huang D, Ou B, Jacob R. 2003. Assay for hydrophilic and lipophilic antioxidant capacity (oxygen radical absorbance capacity $\left(\mathrm{ORAC}_{\mathrm{FL}}\right)$ ) of plasma and other biological and food samples. J Agric Food Chem 51: 3273-3279.

28. Slimestad R. 2003. Flavonoids in buds and young needles of Picea, Pinus and Abies. Biochem Syst Ecol 31: 12471255.

29. Chang TKH, Chen J, Yeung EYH. 2006. Effect of Ginkgo biloba extract on procarcinogen-bioactivating human CYP1 enzymes: identification of isorhamnetin, kaempfer$\mathrm{ol}$, and quercetin as potent inhibitors of CYP1B1. Toxicol Appl Pharmacol 213: 18-26.

30. Susan Marles MA, Ray H, Gruber MY. 2003. New perspectives on proanthocyanidin biochemistry and molecular regulation. Phytochemistry 64: 367-383.

31. Gu L, Kelm MA, Hammerstone JF, Beecher G, Holden J, Haytowitz D, Gebhardt S, Prior RL. 2004. Concentration of proanthocyanidins in common foods and estimations of normal consumption. J Nutr 134: 613-617.

(Received January 14, 2010; Accepted March 9, 2010) 